3. Ettinger D, Wood DE, Aisner DL, et al. NCCN practice guidelines in oncology - non-small cell lung cancer, version 1. Port Washington, PA: National Comprehensive Cancer Network, 2017 (https://www.nccn.org/professionals/physician_gls/f_guidelines .asp).

4. Socinski MA, Bondarenko I, Karaseva NA, et al. Weekly nabpaclitaxel in combination with carboplatin versus solvent-based paclitaxel plus carboplatin as first-line therapy in patients with advanced non-small-cell lung cancer: final results of a phase III trial. J Clin Oncol 2012;30:2055-62.

DOI: 10.1056/NEJMc1615559

THE AUTHORS REPLY: The standard regimen choices in the KEYNOTE-024 trial did not include bevacizumab or nab-paclitaxel. The permitted combinations represent a standard of care in patients with advanced NSCLC worldwide. We do not believe that the addition of bevacizumab or nab-paclitaxel would affect the outcomes because of several factors. First, a very small number of patients received a paclitaxel combination (17 of 150 patients randomly assigned to chemotherapy). Second, although a carboplatin-nabpaclitaxel regimen has shown a higher rate of response than carboplatin-paclitaxel, it did not result in longer survival, even among patients with squamous-cell carcinoma (hazard ratio for death, 0.89 ; $95 \%$ confidence interval, 0.72 to 1.10 ; $\mathrm{P}=0.28) .{ }^{1}$ Third, the introduction of bevacizumab in combination with carboplatin-paclitaxel would have required the introduction of an additional selection factor related to the restricted eligibility criteria for bevacizumab use.

Decisions regarding which contemporary standard therapies to include in lung-cancer trials have become more complex. Issues arise particularly when there are differences with regard to preferred standard therapy across the globe. In this trial, patterns of care show that pemetrexedbased therapy remains a preferred standard for non-squamous-cell histologic type NSCLC and gemcitabine-based therapy remains preferred for squamous-cell histologic type NSCLC.

Martin Reck, M.D., Ph.D.

German Center of Lung Research

Grosshansdorf, Germany

Julie R. Brahmer, M.D.

Sidney Kimmel Comprehensive Cancer Center at Johns Hopkins Baltimore, MD

Since publication of their article, the authors report no further potential conflict of interest.

1. Socinski MA, Okamoto I, Hon JK, et al. Safety and efficacy analysis by histology of weekly nab-paclitaxel in combination with carboplatin as first-line therapy in patients with advanced non-small-cell lung cancer. Ann Oncol 2013;24:2390-6.

DOI: 10.1056/NEJMc1615559

\title{
Abdominal Aortic Aneurysm Repair in England and the United States
}

TO THE EDITOR: Karthikesalingam et al. (Nov. 24 issue $)^{1}$ found a larger diameter of abdominal aortic aneurysm at the time of repair in England than in the United States (mean diameter, 63.8 vs. $58.2 \mathrm{~mm}$ ), as well as higher rates of hospitalization due to aneurysm rupture (odds ratio, 2.23; $\mathrm{P}<0.001$ ) and aneurysm-related death (odds ratio, $3.60 ; \mathrm{P}<0.001)$. As the authors mention, we previously suggested that the size threshold for aneurysm repair should be revisited in the era of endovascular repair. ${ }^{2}$ As the authors correctly state, "The decision about whether to repair an abdominal aortic aneurysm requires consideration of a balance of risks, including aneurysm rupture if surgery is not performed and death due to aneurysm repair itself."

Endovascular aneurysm repair is associated with lower mortality rates than open repair..$^{3-5}$ As a consequence, the balance of risks (risk of an- eurysm rupture vs. risk of death due to aneurysm repair) shifts toward a lower size threshold for repair. ${ }^{2}$ The current study provides the appropriate evidence. Why do the authors think we "would require new clinical trials," and how realistic is it to expect new randomized, controlled trials to answer this question?

\section{Kosmas I. Paraskevas, M.D., Ph.D.}

Freeman Hospital

Newcastle-upon-Tyne, United Kingdom

paraskevask@hotmail.com

Dimitri P. Mikhailidis, M.D.

University College London

London, United Kingdom

No potential conflict of interest relevant to this letter was reported.

1. Karthikesalingam A, Vidal-Diez A, Holt PJ, et al. Thresholds for abdominal aortic aneurysm repair in England and the United States. N Engl J Med 2016;375:2051-9. 
2. Paraskevas KI, Mikhailidis DP, Veith FJ. The rationale for lowering the size threshold in elective endovascular repair of abdominal aortic aneurysm. J Endovasc Ther 2011;18:308-13.

3. Lederle FA, Freischlag JA, Kyriakides TC, et al. Long-term comparison of endovascular and open repair of abdominal aortic aneurysm. N Engl J Med 2012;367:1988-97.

4. Schermerhorn ML, Buck DB, O'Malley AJ, et al. Long-term outcomes of abdominal aortic aneurysm in the Medicare population. N Engl J Med 2015;373:328-38.

5. Dangas G, O'Connor D, Firwana B, et al. Open versus endovascular stent graft repair of abdominal aortic aneurysms: a metaanalysis of randomized trials. JACC Cardiovasc Interv 2012;5: 1071-80.

DOI: $10.1056 / N E J M c 1700463$

TO THE EDITOR: Karthikesalingam et al. used big data ${ }^{1}$ for an "apples with oranges" comparison of the outcomes of abdominal aortic aneurysm in the United States and England, ignoring the likewith-like comparison of randomized trials. Comparisons of big data reflect differences in coding systems, population structure (e.g., age and ethnic group), and total health care expenditure, as well as the indications for surgery. The total expenditure on health care is $16.9 \%$ of the gross domestic product (GDP) in the United States, as compared with $9.3 \%$ of the GDP in England. Very safe nationwide screening programs for abdominal aortic aneurysm in men exist in both England and Sweden, which use a threshold of a $5.5-\mathrm{cm}$ diameter for surgery, with an anticipated doubling of the underlying rate of elective repair of abdominal aortic aneurysm within a few years. ${ }^{2,3}$ Randomized trials of screening and intervention of abdominal aortic aneurysm have included few women, so the $5.5-\mathrm{cm}$ threshold may not be applicable in women.

Therefore, in Europe we may lag a little behind the United States with regard to the time taken to reduce mortality from abdominal aortic aneurysm, but we can achieve similar, evidencebased results at lower cost. Perhaps this is why Karthikesalingam et al. chose not to analyze data after the 2011-2012 period: their results are both misleading and outdated.

Janet T. Powell, M.D., Ph.D.

Imperial College London

London, United Kingdom

j.powell@imperial.ac.uk

No potential conflict of interest relevant to this letter was reported.

1. Gandomi A, Haider M. Beyond the hype: big data concepts, methods, and analytics. Intl J Info Mgmt 2015;35:137-44.

2. Jacomelli J, Summers L, Stevenson A, Lees T, Earnshaw JJ.
Results of the first five years of the NHS Abdominal Aortic Aneurysm Screening Programme in England. Br J Surg 2016;103: 1125-31.

3. Wanhainen A, Hultgren R, Linné A, et al. Outcome of the Swedish nationwide abdominal aortic aneurysm screening program. Circulation 2016;134:1141-8.

DOI: 10.1056/NEJMc1700463

TO THE EDITOR: Karthikesalingam et al. reject likely explanations for their findings of lower rates of abdominal aortic aneurysm rupture and death in the United States than in England, such as differences in aneurysm prevalence and in national reporting methods, and attribute these lower national rates to an explanation that has been excluded by level I evidence - the repair of small aneurysms. Four randomized trials ${ }^{1-4}$ showed no benefit from the elective repair of aneurysms that were less than $5.5 \mathrm{~cm}$ in diameter, making this threshold for repair one of the bestproven tenets of aneurysm management. The authors dismiss these trials because they "began recruitment at least a decade ago, and clinical practice has changed considerably since then." However, in-hospital mortality was lower in three of the four trials ${ }^{2-4}$ than the mortality that the authors now report for the same type of repair in either country. The observations that $39 \%$ of the aneurysms electively repaired in men in the United States are less than $5.5 \mathrm{~cm}$ in diameter and that $17 \%$ are less than $5.0 \mathrm{~cm}$ in diameter describe problems that should be corrected, not exported. These procedures may be good for business, but they are not good for patients.

Frank A. Lederle, M.D.

Veterans Affairs Health Care System

Minneapolis, MN

frank.lederle@va.gov

No potential conflict of interest relevant to this letter was reported.

1. Powell JT, Brown LC, Forbes JF, et al. Final 12-year follow-up of surgery versus surveillance in the UK Small Aneurysm Trial. Br J Surg 2007;94:702-8.

2. Lederle FA, Wilson SE, Johnson GR, et al. Immediate repair compared with surveillance of small abdominal aortic aneurysms. N Engl J Med 2002;346:1437-44.

3. Ouriel K, Clair DG, Kent KC, Zarins CK. Endovascular repair compared with surveillance for patients with small abdominal aortic aneurysms. J Vasc Surg 2010;51:1081-7.

4. Cao P, De Rango P, Verzini F, Parlani G, Romano L, Cieri E. Comparison of Surveillance versus Aortic Endografting for Small Aneurysm Repair (CAESAR): results from a randomised trial. Eur J Vasc Endovasc Surg 2011;41:13-25.

DOI: $10.1056 /$ NEJMc1700463 